Canadian Oncology

Nursing Journal

Revue canadienne

de soins infirmiers

en oncologie

Volume 31, Issue 3 • Summer 2021

elSSN: 2368-8076 


\title{
Knowledge, utilization and barriers of cervical cancer screening among women attending selected district hospitals in Kigali - Rwanda
}

\author{
by Gaudence Niyonsenga, Darius Gishoma, Ruth Sego, Marie Goretti Uwayezu, Bellancille Nikuze, Margaret Fitch, Pierre \\ Céléstin Igiraneza
}

\section{ABSTRACT}

Background: Cervical cancer is the third most common cancer attacking women globally, and the second in Eastern Africa where Rwanda is located. Regular screening is an effective prevention approach for cervical cancer. Despite that, the screening rate for cervical cancer in Africa is estimated between $10 \%$ and $70 \%$, with a number of barriers. This is especially the case in sub-Saharan Africa. In Rwanda, there is limited literature on the rate of use of screening services or the barriers to cervical screening.

\section{AUTHOR NOTES}

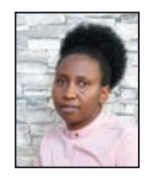

Gaudence Niyonsenga:' King Faisal Hospital, Kigali, Rwanda

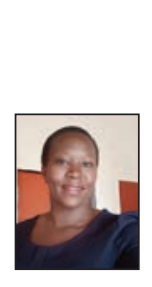

Darius Gishoma, School of Nursing and Midwifery, University of Rwanda, College of Medicine and Health Sciences, Kigali, Rwanda

\section{Ruth Sego, Rory Meyer's College of Nursing, New York} University, New York, USA and the Bloomberg Faculty of Nursing, University of Toronto, Canada

Marie Goretti Uwayezu, School of Nursing and Midwifery, University of Rwanda, College of Medicine and Health Sciences, Kigali, Rwanda

Bellancille Nikuze, School of Nursing and Midwifery, University of Rwanda, College of Medicine and Health Sciences, Kigali, Rwanda Margaret Fitch, School of Nursing and Midwifery, University of Rwanda, College of Medicine and Health Sciences, Kigali, Rwanda

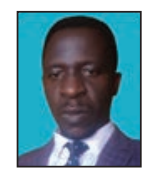

Pierre Céléstin Igiraneza, Alight Rwanda, Nyabiheke Refugee Camp, Rwanda

${ }^{*}$ Corresponding author: Gaudence Niyonsenga, King Faisal Hospital, Kigali, Rwanda

Email: niyosavior@gmail.com

Author's contribution: All authors have contributed to the final version of the paper.

Acknowledgement: I am grateful to Dr. Darius Gishoma and Ruth Sego for the scientific assistance during this research.

DOI: $10.5737 / 23688076313266274$
Objective: To assess knowledge, utilization, and barriers of cervical cancer screening among women attending selected district hospitals in Kigali, Rwanda.

Methods: A descriptive cross-sectional study with a structured questionnaire was used to collect data. Nominal 'yes' or 'no' questions were used to gather data on knowledge and utilisation of cervical cancer and its screening. Likert-type scale questions were used to identify different barriers to screening services. Data were analysed using descriptive and inferential statistics. Respondents were selected by systematic random sampling from the database of women attending gynaecology services at three district hospitals in Kigali, Rwanda.

Results: Three hundred and twenty-nine women responded to the survey. Half of the respondents $(n=165)$ had high knowledge level scores on cervical cancer screening. The cervical cancer screening rate was $28.3 \%$. Utilization of screening was associated with knowledge $(P=0.000, r=-0.392)$ and selected demographic factors $(P=0.000)$. Individual barriers included poor knowledge on availability of screening services, community barriers included living in a rural area, and health provider and systems barriers included lack of awareness campaigns, negative attitudes of healthcare providers toward clients, and long waiting times; all barriers limit the access to screening services.

Conclusion: A low rate of cervical cancer screening was identified for women attending selected district hospitals in Kigali-Rwanda due to various barriers. On-going education on cervical cancer and its screening is highly recommended. It is important that trained health providers encourage their clients to have cervical cancer screening and work to reduce related barriers.

Keywords: cervical cancer, cervical screening, utilization of cervical screening, knowledge about screening, barriers to screening, screening in LMIC

\section{BACKGROUND}

W orldwide, cervical cancer is the third most common cancer affecting women (Ferlay et al., 2019). The main cause of cervical cancer is the human papilloma virus (HPV; de Sanjosé et al., 2018). Screening for cervical cancer is a quick response intervention for incidence reduction to the human papilloma virus precancerous lesions (Stewart et al., 2018). The screening methods include visual inspection of precancerous lesions using Lugol's iodine (VILI), visual inspection using acetic acid (VIA), and cytology-based screening or HPV testing (Stewart et al., 2018; Ferlay et al., 2019). However, in low income countries, screening based on searching human 
papilloma virus DNA or cytology is still not affordable (Stewart et al., 2018; Mukanyangezi et al., 2017). Trained health providers (i.e., nurses, midwives and doctors) are able to do procedures such as of VIA and VILI (Ruzigana et al., 2017).

Screening methods focus on detecting precancerous lesions, which could lead to cancer if not treated (Ruzigana et al., 2017). The World Health Organization (WHO) recommends women start cervical cancer screening at 30 years of age (Santesso et al., 2016; Ferlay et al., 2019). The interval periods between screening vary from three to five years, for women with negative screening on VIA or cytology (Curry et al., 2018). On the other hand, women identified with abnormal cervical lesions on screening are scheduled for further regular checks, diagnosis, and treatment. Further and regular follow-up prevent the growth of cancer and allow treatment at an early stage, which increases chance of healing (Stewart et al., 2018).

Despite early detection of cervical cancer being associated with an increased survival rate (Vaccarella et al., 2017), Schiffman (2017) showed how females from sub-Saharan Africa still have advanced cases of cancer that are untreatable (Schiffman, 2017). Late detection of cervical cancer usually denies women early curative treatment, thus increasing morbidity and mortality rates (Makuza et al., 2015; Stewart et al., 2018). In studies conducted in some African countries, among women, the rates of using cervical screening services were low, as in low income and lower-middle income countries (Stewart et al., 2018). Studies reported screening rates of $0.8 \%, 5 \%$, and $5.3 \%$ in coastal Ghana, Sudan, and Nigeria respectively (Almobarak et al., 2016; Kokuro, 2017; Ebu et al., 2014), against $75 \%$ in upper-income and upper-middle income countries (Nwobodo \& Ba-Break, 2016).

Regarding screening services in Rwanda, a population risk factor analysis in sub-Saharan Africa reported a population coverage in cervical cancer screening between $10 \%$ and 50\% (Govindaraj et al., 2015). In addition, research findings from the neighbouring countries of Eastern Africa, showed cervical cancer screening rates were still low (Stewart et al., 2018; Kangmennaang, et al., 2018; Almobarak et al., 2016). According to Kangmennaang et al. (2018), Kenya stands at $14 \%$ of women in reproductive ages screened, and Uganda's rates are between $4.8 \%$ and $39 \%$; screening rates in Tanzania were between $6 \%$ and $23 \%$ and, in the Democratic Republic of Congo, were at 20.2\% (Kangmennaang et al., 2018; Nakisige et al., 2017 Cunningham et al., 2015; Almobarak et al., 2016).

Researchers in different settings and countries reported a variety of barriers affecting cervical cancer screening (Bateman et al., 2019; Zidar et al., 2015; Titiloye et al., 2017; Compaore et al., 2016). The barriers mostly related to the client (patients seeking cervical cancer services), provider (healthcare providers), and systems (health polices, access and availability of services within a given country; Racey \& Gesink, 2016; Bateman et al., 2019; Almobarak et al., 2016; McFarland et al., 2016). In Rwanda, factors that delayed patients from consultation about treatment had been demonstrated by Benemariya (2018) and Manirakiza (2016). Women with cervical cancer were delayed in seeking medical treatment due to patient, healthcare provider, and healthcare system factors (Benemariya et al., 2018; Manirakiza et al., 2016).
Given the low rates of screening in Rwanda, the present research assessed level of knowledge, utilization, and barriers to cervical cancer screening services of women attending gynecological services from selected district hospitals in Kigali, Rwanda. Results would help to develop relevant intervention strategies to increase screening rates and facilitate early detection of precancerous cervical lesions in women in this country.

\section{METHODS}

\section{Design and setting}

A descriptive cross-sectional study was conducted in gynaecology services of three district hospitals in Kigali, Rwanda (i.e., Muhima, Masaka, and Kibagabaga district hospitals).

\section{Participant recruitment}

The accessible study population included women attending gynaecology services from May 1-30, 2019 at selected district hospitals. The hospitals' databases showed an average of 2,292 women attended the gynaecology services in the month (Rwanda Integrated Health Management Information System, 2019). This was defined as the eligible study population. Using the Cochrane formula, a required sample size of 329 participants was calculated with a confidence level of $95 \%$, and significance level of 0.005. Sample selection used a systematic sampling technique. The total of 329 women between 30 years and 60 years of age were selected from all women attending the hospitals' gynaecology service based on sampling each seventh women presented. Women were approached by the researcher as they came to the service appointment and, if they met the study criteria, asked to participate.

\section{Measures}

The questionnaire was adapted from a validated Cervical Cancer Awareness Measure developed by Cancer Research United Kingdom. A study conducted in Tanzania using the same measure to assess knowledge about cervical cancer prevention and screening practices found low levels of knowledge with low screening rates among study respondents (Mabelele et al., 2018).

The questionnaire included six nominal questions about sociodemographic characteristics of participants including Ubudehe categories (defined as socioeconomic clusters, where the higher was the number, the wealthier was the family), and 10 nominal and yes/no questions on knowledge of screening. Three questions focused on the utilization of screening services. A final Likert scale question emphasized barriers to cervical screening related to the individual, community, health system, and healthcare provider.

The final tool was translated into Kinyarwanda as the local language, to reflect terms respondents could understand. The supervisors of the study and two linguistic experts reviewed the translated version before data collection. A pilot study was conducted with seven women, who did not appear as participants of the full study, in order to test the feasibility of the study. Cronbach's alpha was calculated using the SPSS software package. Acceptable values of alpha range from 0.70 to 0.95 (Tavakol \& Dennick, 2011). In this study, Cronbach's alpha of the research instrument was calculated to be 0.8 . 


\section{Data collection}

The structured questionnaire collected quantitative data. Data collection was completed by the researcher aided by data enumerators. For the sake of ethical considerations and data quality, relevant information for the study was explained to the women, and they were asked to give their consent by signing the form to participate in the study. The completion of the questionnaire by the researcher asking the women the questions took 10 to 15 minutes.

\section{Data analysis}

Data collected from respondents was sorted, then coded in the datasheet created in SPSS version 17, 2016 software. Descriptive statistics were used to calculate frequencies for the demographic, knowledge, and utilization variables. Pearson Correlation was applied to assess the association of knowledge scores against selected demographic variables and utilization. To establish the knowledge score, a dummy variable was calculated, where 1 stands for the correct answer, and 0 stands for the wrong answer. The overall score was the sum of ten dummy questions. The scores were grouped into the five categories of knowledge scores. The 'very low' level scored zero to two points, 'low' level stood between three and four, 'moderate' level was five to six, 'high' level scored seven to eight, and 'very high' level of knowledge was nine to ten. For the barrier question, Likert scale mean calculation was calculated and used to identify the most apparent barriers to cervical screening.

\section{Ethical consideration}

The University of Rwanda, College of Medicine and Health Sciences, Institutional Review Board, and the ethical committees at the three district hospitals approved the study. All study participants signed the consent form before data collection.

\section{RESULTS}

\section{Characteristics of respondents}

The majority of the respondents were married $(77.5 \%)$, lived in an urban area (65.7\%), belonged in the 3rd category of Ubudehe (55.9\%) (middle class of income; among four categories whereby first and second categories are considered to be the people with lowest income) and nearly half (46.5\%) were between 30-35 years of age. More than a third of respondents (44.1\%) had a primary level education, and one-third were adherents of the Catholic religion (31\%) (see Table 1).

\section{Knowledge on cervical cancer and its screening}

Half of the respondent had a high level of knowledge, as they responded correctly to seven to 10 questions, about cervical cancer and its screening. They knew the cause of cervical cancer as human papilloma virus (49.5\%) and prevention measures of early screening (43.5\%) and vaccination (40.8\%). The symptoms of cervical cancer were known as follows; vaginal bleeding (26.4\%), and foul-smelling vaginal discharge (21.5\%). The bestknown risk factors of cervical cancer were many sexual partners $(15.8 \%)$ and early onset of sexual activity (14.6\%). Cervical cancer screening coverage among respondents was $28.3 \%$, and amongst those screened, the majority $(95.7 \%)$ received the service in public institutions (hospitals and health centres) (see Table 2).

\begin{tabular}{|c|c|}
\hline \multicolumn{2}{|c|}{ Table 1: Selected Social Demographic Characteristics } \\
\hline Age of respondents & $n(\%)$ \\
\hline $30-35$ & $153(46.5)$ \\
\hline $36-40$ & $87(26.4)$ \\
\hline $41-45$ & 39 (11.9.) \\
\hline $46-50$ & $25(7.6)$ \\
\hline $51-55$ & $25(7.6)$ \\
\hline \multicolumn{2}{|l|}{ Religion of respondents } \\
\hline Catholic & $102(31)$ \\
\hline Protestant & $50(15.2)$ \\
\hline Muslim & $17(5.2)$ \\
\hline Pentecostal & $92(28.0)$ \\
\hline Seventh Day Adventist & $50(15.2)$ \\
\hline Other & $18(5.5)$ \\
\hline \multicolumn{2}{|l|}{ Education level } \\
\hline None & $24(7.3)$ \\
\hline Primary (P1 to P6) & $145(44.1)$ \\
\hline O level (S1 to S3) & $46(14.0)$ \\
\hline A level (S3 to S6) & $70(21.3)$ \\
\hline Tertiary education/University & $44(13.4)$ \\
\hline \multicolumn{2}{|l|}{ Marital status } \\
\hline Single & $40(12.2)$ \\
\hline Married & $255(77.5)$ \\
\hline Widowed & $25(7.6)$ \\
\hline Divorced/Separated & $9(2.7)$ \\
\hline \multicolumn{2}{|l|}{$\begin{array}{l}\text { Ubudehe category (socio-economic } \\
\text { classes) }\end{array}$} \\
\hline Category 1 & $40(12.2)$ \\
\hline Category 2 & $105(31.9)$ \\
\hline Category 3 & $184(55.9)$ \\
\hline \multicolumn{2}{|l|}{ Place of residence } \\
\hline Rural sector & $113(34.3)$ \\
\hline Urban sector & $216(65.7)$ \\
\hline
\end{tabular}


Association between sociodemographic characteristic, knowledge and utilization

Findings demonstrated an association between education level and knowledge about the cause of cervical cancer $(\mathrm{r}=-0.2726, p=0.000)$, prevention of cervical cancer $(\mathrm{r}=-0.155$, $p=0.000)$, curable outcome when detected early $(\mathrm{r}=0.107$, $p=0.003)$, and knowledge on availability of cervical screening service in Rwanda $(\mathrm{r}=0.167, p=0.000)$. Statistical testing demonstrated a strong association between knowledge and screening services utilization $(r=-0.392, p=0.000)$ (see Table 3$)$.
Individual, community, health provider and health system barriers to cervical cancer screening services

Individual barriers to cervical cancer screening were identified as poor knowledge about the availability of cervical cancer screening services $(67.5 \%$, Likert-scale mean=3.6), followed by the lack of information about the importance of cervical cancer screening (agreed $=63.5 \%$, Likert scale mean $=3.3$ ). In the same context, $54.2 \%$ (Likert scale mean $=3.4$ ) of respondents confirmed that the worry and fear of cervical cancer screening prevents women from using the service. Community-related

Table 2: Summary of knowledge about cervical cancer, its screening, and utilisation of screening services $(N=329)$

\begin{tabular}{|c|c|c|}
\hline Items on Questionnaire & Frequency & Percent \\
\hline \multicolumn{3}{|l|}{ Primary risk factors of cervical cancer } \\
\hline Human papilloma virus & 163 & 49.5 \\
\hline Don't know & 166 & 50.5 \\
\hline \multicolumn{3}{|l|}{ Other risk factors for cervical cancer } \\
\hline Don't know & 6 & 0.4 \\
\hline Smoking & 136 & 9 \\
\hline Many sexual partners & 238 & 15.8 \\
\hline Human papilloma virus (HPV) & 143 & 9.5 \\
\hline Sexually transmitted diseases & 170 & 11.3 \\
\hline Human immunodeficiency virus (HIV) & 127 & 8.4 \\
\hline Early onset of sexual activity & 220 & 14.6 \\
\hline Family history of cervical cancer & 150 & 10 \\
\hline Uncircumcised male partner & 163 & 10.8 \\
\hline Use contraceptive pills for a long time & 153 & 10.2 \\
\hline \multicolumn{3}{|l|}{ Cervical cancer be prevented } \\
\hline Yes & 273 & 83 \\
\hline No & 22 & 6.7 \\
\hline Don't know & 34 & 10.3 \\
\hline \multicolumn{3}{|l|}{ Cervical cancer curable if detected early } \\
\hline Yes & 297 & 90.3 \\
\hline No & 12 & 3.7 \\
\hline Don't know & 20 & 6.1 \\
\hline \multicolumn{3}{|l|}{ Cervical cancer preventive measures } \\
\hline Early screening & 194 & 43.5 \\
\hline Avoiding smoking & 29 & 6.5 \\
\hline Vaccination & 182 & 40.8 \\
\hline Nothing can be done & 3 & 0.7 \\
\hline Avoiding sexual intercourse & 4 & 0.9 \\
\hline Don't know & 34 & 7.6 \\
\hline
\end{tabular}

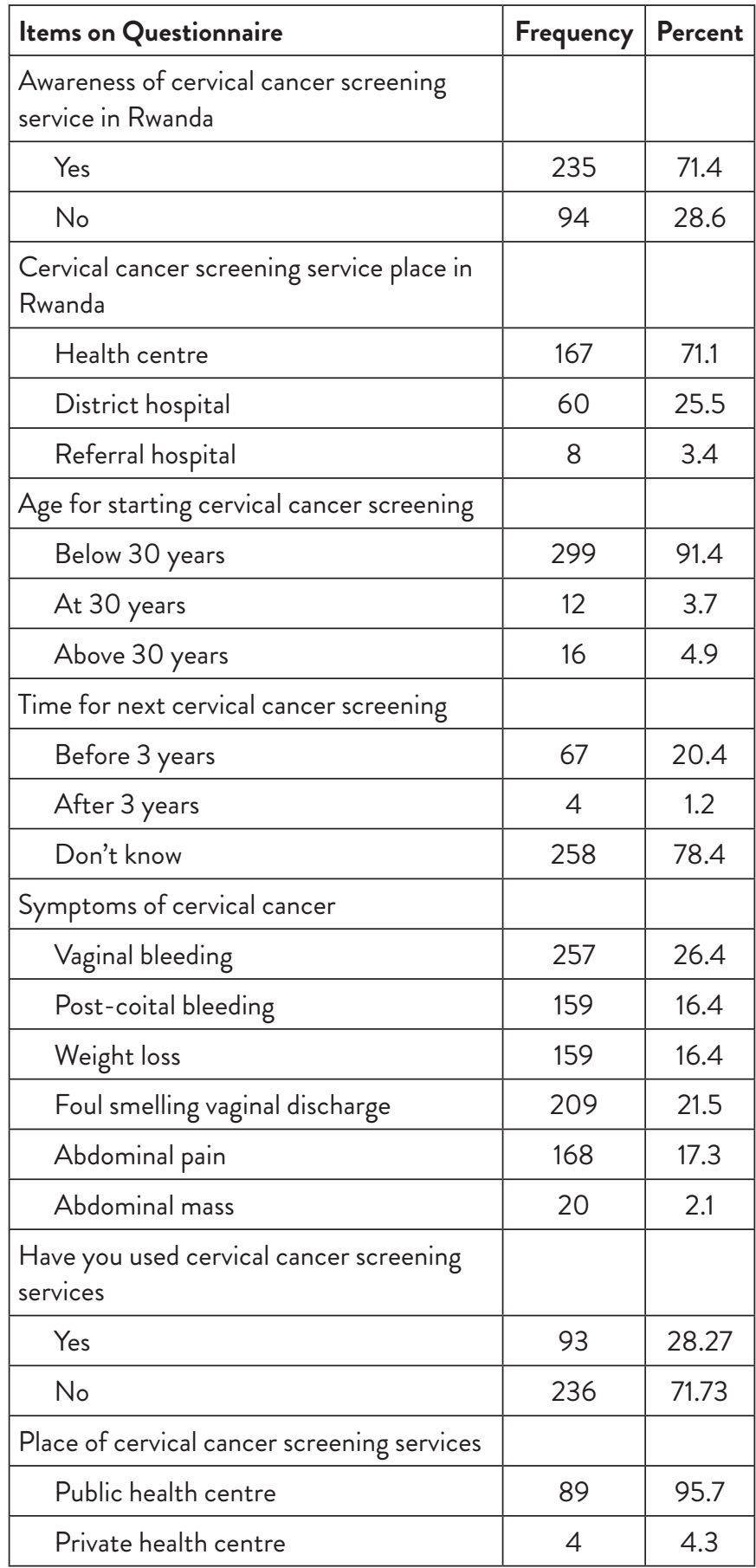




\begin{tabular}{|c|c|c|c|c|c|c|c|}
\hline & Very low & Low & Moderate & High & Very high & $\mathbf{X}^{2}$ & $p$ value \\
\hline \multicolumn{8}{|l|}{ Age group } \\
\hline$[30-35]$ & 1.31 & 11.76 & 26.8 & 52.94 & 7.19 & & \\
\hline$[36-40]$ & 0 & 13.79 & 41.38 & 37.93 & 6.9 & 24.823 & 0.073 \\
\hline$[41-45]$ & 0 & 15.38 & 28.21 & 46.15 & 10.26 & & \\
\hline$[46-50]$ & 0 & 8 & 16 & 76 & 0 & & \\
\hline [51-55] & 0 & 8 & 16 & 56 & 20 & & \\
\hline \multicolumn{8}{|l|}{ Education } \\
\hline None & 0 & 8.33 & 62.5 & 29.17 & 0 & & \\
\hline Primary (P1 to $P 6)$ & 0 & 12.41 & 40.69 & 42.07 & 4.83 & & \\
\hline O level (S1 to S3) & 0 & 17.39 & 13.04 & 60.87 & 8.7 & 66.545 & 0.000 \\
\hline A level (S3 to S6) & 2.86 & 11.43 & 17.14 & 62.86 & 5.71 & & \\
\hline Tertiary education/Un & 0 & 9.09 & 9.09 & 56.82 & 25 & & \\
\hline \multicolumn{8}{|l|}{ Marital Status } \\
\hline Single & 5 & 15 & 35 & 37.5 & 7.5 & & \\
\hline Married & 0 & 12.55 & 27.06 & 52.94 & 7.45 & 27.557 & 0.006 \\
\hline Widowed & 0 & 0 & 32 & 52 & 16 & & \\
\hline Divorced/Separated & 0 & 22.22 & 55.56 & 22.22 & 0 & & \\
\hline \multicolumn{8}{|c|}{ Ubudehe(socio-economic clusters) } \\
\hline First group & 0 & 25 & 25 & 50 & 0 & & \\
\hline Second group & 0 & 5.71 & 34.29 & 53.33 & 6.67 & 17.198 & 0.028 \\
\hline Third group & 1.09 & 13.04 & 27.17 & 48.37 & 10.33 & & \\
\hline \multicolumn{8}{|l|}{ Place of residence } \\
\hline Rural sector & 0 & 10.62 & 31.86 & 52.21 & 5.31 & 3.415 & 0.419 \\
\hline Urban sector & 0.93 & 12.96 & 27.78 & 49.07 & 9.26 & & \\
\hline \multicolumn{8}{|l|}{ Utilization } \\
\hline Yes & 0 & 0 & 10.75 & 74.19 & 15.05 & 54.968 & 0.000 \\
\hline No & 0.85 & 16.95 & 36.44 & 40.68 & 5.08 & & \\
\hline
\end{tabular}

barriers were reported as living in rural areas $(51.9 \%$, Likert scale mean $=3.1$ ), and social stigmatization related to cancer disease $(49.4 \%$, Likert scale mean $=3.2)$.

Healthcare provider-related barriers included lack of awareness campaigns on cervical cancer screening $(59.0 \%$, Likert scale mean $=3.1$ ), and negative attitudes about health providers toward clients (agreed $=46.5 \%$; Likert scale mean $=3.2$ ). Having to wait a long time in order to have the cervical cancer screening performed was reported as a barrier to cervical cancer screening by $64.1 \%$ of the respondents (Likert scale mean $=3.6$ ). Women having to come a long distance before reaching centres for cervical cancer screening was seen as a barrier by $58.7 \%$ (Likert scale mean mean $=3.2$ ). Lastly, an issue of health insurance was reported as a barrier to cervical cancer screening by $51.4 \%$ (Likert scale mean mean $=3.2$ ) of the respondents (see Table 4).

\section{DISCUSSION}

For the current study, the majority of respondents were married and lived in an urban area; nearly half were between $30-35$ years of age. This sample is similar to a Nigerian study where the mean age was 30 ( $\mathrm{SD}=6.8$ ) and $70.9 \%$ of the participants were married (Titiloye et al., 2017). This reflects a relevant population for cervical screening. 
Table 4: Analysis of barriers to cervical cancer screening

\begin{tabular}{|c|c|c|c|c|c|}
\hline Barriers & Disagree \% & Not sure $\%$ & Agree \% & Mean \% & Std. Dev. \\
\hline \multicolumn{6}{|l|}{ Individual related } \\
\hline Not being aware of availability of screening service & 27.1 & 5.5 & 67.5 & 3.6 & 1.3 \\
\hline Feeling painful while screening & 41.2 & 43.0 & 15.8 & 2.6 & 1.0 \\
\hline Participating in cancer screening makes one worry & 27.8 & 18.0 & 54.2 & 3.4 & 1.2 \\
\hline Much money needed for treatment & 76.1 & 7.3 & 16.6 & 1.9 & 1.2 \\
\hline $\begin{array}{l}\text { Physically healthy women do not need cervical cancer } \\
\text { screening }\end{array}$ & 80.4 & 4.2 & 15.4 & 2.0 & 1.1 \\
\hline Gender norms & 68.8 & 12.5 & 18.7 & 2.3 & 1.1 \\
\hline Cultural norms & 68.8 & 11.4 & 19.9 & 2.2 & 1.1 \\
\hline Community organization and myth & 72.1 & 15.4 & 12.5 & 2.2 & 1.1 \\
\hline Social stigmatization & 42.8 & 7.8 & 49.4 & 3.2 & 1.5 \\
\hline Living in rural area & 43.0 & 5.1 & 51.9 & 3.1 & 1.4 \\
\hline \multicolumn{6}{|l|}{ Service provider related } \\
\hline Lack of awareness campaign on screening & 38.2 & & 59.0 & 3.1 & 1.6 \\
\hline \multicolumn{6}{|l|}{ Health system related } \\
\hline Health facilities located far from home (long distance) & 35.9 & & 58.7 & 3.2 & 1.2 \\
\hline Poor trust in the services offered at health facilities & 55.2 & & 30.5 & 2.6 & 1.3 \\
\hline Unavailability of screening services & 51.7 & & 37.4 & 2.6 & 1.3 \\
\hline Lack of health insurance & 39.8 & & 51.4 & 3.2 & 1.2 \\
\hline Absence of treatment at nearest facility & 60.2 & & 28.9 & 2.7 & 1.3 \\
\hline Lack of health materials for cancer treatment & 43.8 & & 39.8 & 3.0 & 1.1 \\
\hline Long waiting time for screening & 25.0 & & 64.1 & 3.6 & 1.3 \\
\hline
\end{tabular}

\section{Knowledge on cervical cancer and its screening}

The current study found that half of the respondent have a high level of knowledge on cervical cancer and its screening. Moreover, respondents had knowledge of Human Papilloma Virus as the cause or primary risk factor of cervical cancer (49.5\%), and knew early screening (43.5\%), and vaccination $(40.8 \%)$ as prevention measures. However, some symptoms, such as post-coital bleeding, and some of the risk factors of cervical cancer (e.g., smoking, uncircumcised male partner, and family history of cervical cancer) were not widely known by study participants.

The findings agree with a study conducted in Cameroon which showed that $37 \%$ of the participants were able to identify the cause and risk factors of cervical cancer (Halle-Ekane et al., 2018). Findings about the symptoms of cancer of the cervix were similar to what was found in Tanzania where 
persistent smelling of vaginal discharge, persistent pelvic pain, vaginal bleeding, and discomfort during sexual activity were the best known symptoms of cervical cancer (Mabelele et al., 2018; Santesso et al., 2016). This study also showed similarity with a study conducted in Burkina Faso where $90 \%$ of respondents had heard about cervical cancer and 55\% had intermediate knowledge on the disease, its screening and risk factors (Compaore et al., 2016).In contrast, a study conducted in Sudan found that less than a half of the study participants had adequate knowledge on cervical cancer, HPV, and cervical cancer screening (Almobarak et al., 2016) and a study in Nepal showed only $38 \%$ had adequate knowledge on cervical cancer screening services (Thapa et al., 2018).

\section{Cervical cancer screening services utilization}

This research identified that $28.3 \%$ of women had undergone cervical cancer screening services. Among them, 95.7\% had used screening services in Public Health facilities. The screening rate is in the range reported in a population risk factor analysis in sub-Saharan Africa which highlighted that the Rwandan population coverage in cervical cancer screening ranged from $10 \%$ to $50 \%$ of women (Stewart et al., 2018). However, this present study finding contradicts other study findings from Cameroon where $4.8 \%$ of University students confirmed their participation in Pap smear cervical screening (Halle-Ekane et al., 2018) and in Nigeria where the cervical cancer coverage was $15.6 \%$ among reproductive age women (Titiloye et al., 2017). The sub-Saharan Africa study showed coverage of cancer screening ranged from 0.0 to $50 \%$ (Stewart et al., 2018).

Liebermann et al. (2018) reported a good association between participation in Pap smear screening and level of income (Liebermann et al., 2018). Rural residency was also found to be a significant predictor of Pap smear screening participation in contrast to urban residency. Women with elementary or lower educational level are at higher risk for being limited in accessing participation in Pap smear screening (Liebermann et al., 2018). Employment status and level of knowledge have also been reported as factors affecting good adoption of screening services (Compaore et al., 2016).

\section{Sociodemographic characteristic associated with knowledge and utilization}

This research demonstrated a significant association between cancer screening services uptake and education level, marital status, and high level of knowledge $(\mathrm{P}=0.000)$. These findings are similar to what was observed in Nepal where adequate knowledge of respondents was related to Pap smear testing, and the literate females had increased rates of cervical cancer screening (Thapa et al., 2018).

These study findings are also similar to research conducted on Indonesian women where awareness of cancer screening and socioeconomic values (including level of education, expenditure at household level, health insurance coverage, menopausal status, and morbidity) were found to be associated with Pap smear participation (Anwar et al., 2018). The findings were also similar to a study in Tanzania on knowledge about cervical cancer prevention and screening practices among women who attended a reproductive and child health clinic (Mabelele et al., 2018). That study demonstrated that formal employment, marital status, high number of parity, and access to health insurance are demographic characteristics associated with level of knowledge on cervical screening (Mabelele et al., 2018). Research from Burkinafaso also demonstrated that level of knowledge affected women's adoption of cancer screening (Compaore et al., 2016). Moreover, in sub-Saharan Africa, lack of awareness, non-formal education, high parity, level of positive HIV, and non-use of condoms were risk factors for late stage presentation of cervical cancer (Stewart et al., 2018). However, our findings differ from those found in Nigeria, where the level of knowledge was not associated with the utilization of cervical cancer screening (Titiloye et al., 2017).

\section{Individual, community, health provider and health system barriers to cervical cancer screening services}

These research findings from different district hospitals of Rwanda demonstrated a number of barriers at the individual level for cancer screening among women attending gynaecological services. Findings were confirmed by other researchers from different countries and different research settings. The most important individual barriers to participation in screening services are poor access to information and low level of knowledge about the importance of screening. In Cameroon, research conducted on women students from the University of Buea, showed that lack of access to screening services, treatment and accurate information were limiting factors to attending a screening service (Bateman et al., 2019 Halle-Ekane et al., 2018). A systematic study on barriers limiting screening services in sub-Sahara Africa demonstrated lack of information about cervical cancer screening practice as a limiting factor. In Burkina Faso, research among immigrant females and minority groups of people also found lack of awareness on screening services was a barrier to service. In addition to the lack of awareness by women across sub-Saharan Africa, having a large number of females infected by HIV, with non-formal education, high parity, and high incidence of unsafe sex were identified as potential factors predicting late-stage presentation of women with cervical cancer (Stewart et al., 2018).

One other important individual barrier, determined in the present study, was worries associated with women's privacy. Three other studies in Africa demonstrated that emotional (defined as fear or shyness), embarrassment, painful procedure, possible violation of privacy, and reliance on prayer with the onset of illness were the major factors preventing women from attending the screening services (Dutta, Haderxhanaj, \& Agley, 2018, Kangmennaang et al., 2018; Lim \& Ojo, 2017).

The present research indicated that social stigmatization and living in a rural area affected cancer screening services. These findings resemble those reported for Ugandan women through a systematic review that showed residing in a remote or rural area was a barrier to having the cervical cancer screening procedure (Black, Hyslop, \& Richmond, 2019). In Tanzania, a similar study showed cervical cancer screening was associated with stigma and isolation (Mabelele et al., 2018). The stigma comes from women's fears and worries 
about participating in cancer screening (Bateman et al., 2019). Different societies have different cultural and beliefs at individual, couple, family, and society levels. Those differences can become cervical screening barriers and influence Pap smear screening. From other studies, the common screening barriers were embarrassment, fear, and perceived pain of the Pap test (Liebermann et al., 2018).

In this research, $59 \%$ of women respondents were limited in their awareness about cervical cancer screening by the absence of awareness campaigns. Mukanyangezi (2018) identified poor access to information and financial capabilities as the most common reasons preventing HIV positive women from performing cancer screening (Mukanyangezi et al., 2017). In this current study, long distances to the health facility and long waiting times for the procedure were found to be barriers in cervical cancer screening. Likewise, patients, health providers, health care system factors were denoted by Benemariya (2018) as affecting late consultation for cancer of cervix and their treatment in Rwanda (Benemariya et al., 2018). The present study findings confirm in Rwanda what researchers in other African countries have demonstrated.

\section{LIMITATIONS}

Several limitations exist in this study. Firstly, there was low coverage of the country due to limited time and resources. Secondly, research was conducted with females from selected district hospitals in an urban setting, which may differ in patient populations. This sample is not representative of women country wide. Nearly $50 \%$ of women recruited in this study attended at least secondary school and others had university studies. This could indicate that respondents might be

\section{REFERENCES}

Almobarak, A. O., Elbadawi, A. A., Elmadhoun, W. M., Elhoweris, M. H., \& Ahmed, M. H. (2016). Knowledge, attitudes and practices of sudanese women regarding the Pap smear test and cervical cancer. Asian Pacific Journal of Cancer Prevention, 17(2), 625-630. https:// doi.org/10.7314/APJCP.2016.17.2.625

Anwar, S. L., Tampubolon, G., Van Hemelrijck, M., Hutajulu, S. H., Watkins, J., \& Wulaningsih, W. (2018). Determinants of cancer screening awareness and participation among Indonesian women. BMC Cancer, 18(1), 1-11. https://doi.org/10.1186/s12885-018-4125-z

Bateman, L. B., Blakemore, S., Koneru, A., Mtesigwa, T., McCree, R., Lisovicz, N. F., ... Jolly, P. E. (2019). Barriers and facilitators to cervical cancer screening, diagnosis, follow-up care and treatment: Perspectives of Human Immunodeficiency Virus-Positive Women and Health Care Practitioners in Tanzania. The Oncologist, 24(1), 69-75. https://doi.org/10.1634/theoncologist.2017-0444

Benemariya, E., Chironda, G., Nkurunziza, A., Katende, G., Sego, R., \& Mukeshimana, M. (2018). International Journal of Africa Nursing Sciences perceived factors for delayed consultation of cervical cancer among women at a selected hospital in Rwanda : An exploratory qualitative study. International Journal of Africa Nursing Sciences, 9(October), 129-135. https://doi.org/10.1016/j. ijans.2018.10.006

Black, E., Hyslop, F., \& Richmond, R. (2019). Barriers and facilitators to uptake of cervical cancer screening among women in Uganda: A systematic review. BMC Women's Health, 19(1), 1-12. https://doi. org/10.1186/s12905-019-0809-z literate and more conscious about their health when compared with other groups of women in rural areas. Thus, results need cautious interpretation before their generalization to the entire population of the country.

\section{RECOMMENDATIONS}

Several key recommendations emerge from this study. There is a need for on-going education and mobile screening campaigns in remote areas aiming to provide information for the general population about cervical cancer and its screening. Massive training of health providers at the primary level of the health system about cervical cancer and its screening may help to improve the way health providers recommend cervical cancer screening to women. Availability of cervical screening service at all levels of the health system is a crucial element. The same study needs to be repeated in other locations of the country.

\section{CONCLUSION}

The present research was conducted with women attending gynaecology services in selected district hospitals in Kigali, Rwanda. The findings highlight the low rate of cervical cancer screening uptake and barriers related to individuals, communities, health providers, and health system. Based on study findings, there is a need to educate the general population about cervical cancer and its screening and recommend cervical cancer screening to women. Health facilities need to keep cervical cancer screening available, accessible, and affordable for relevant age groups, thus implementing the national cervical cancer screening program. Further study should be focused on the quality of education and cervical cancer screening service offered to women in different locations.

Compaore, S., Ouedraogo, C. M. R., Koanda, S., Haynatzki, G., Chamberlain, R. M., \& Soliman, A. S. (2016). Barriers to cervical cancer screening in Burkina Faso. J Cancer Educ, 31(4), 760-766. https://doi.org/10.1007/s13187-015-0898-9 T4 - Needs for Patient and Professional Education PM - 26336956 M4 - Citavi

Cunningham, M. S., Skrastins, E., Fitzpatrick, R., Jindal, P., Oneko, O., Yeates, K., ... Aronson, K. J. (2015). Cervical cancer screening and $H P V$ vaccine acceptability among rural and urban women in Kilimanjaro Region, Tanzania. BMJ Open, 5(3), 1-9. https://doi. org/10.1136/bmjopen-2014-005828

Curry, S. J., Krist, A. H., Owens, D. K., Barry, M. J., Caughey, A. B., Davidson, K. W., ... Wong, J. B. (2018). Screening for cervical cancer: US preventive services task force recommendation statement. JAMA - Journal of the American Medical Association, 320(7), 674-686. https://doi.org/10.1001/jama.2018.10897

de Sanjosé, S., Brotons, M., \& Pavón, M. A. (2018). The natural history of human papillomavirus infection. Best Practice and Research: Clinical Obstetrics and Gynaecology, 47, 2-13. https://doi. org/10.1016/j.bpobgyn.2017.08.015

Dutta, T., Haderxhanaj, L., \& Agley, J. (2018). Association between individual and intimate partner factors and cervical cancer screening in Kenya. Centers for Disease Controal and Prevention : Preventing Chronic Disease, 15, 1-9.

Ebu, N. I., Mupepi, S. C., Siakwa, M. P., \& Sampselle, C. M. (2014). Knowledge, practice, and barriers toward cervical cancer screening 
in Elmina, Southern Ghana. International Journal of Women's Health, 7, 31-39. https://doi.org/10.2147/IJWH.S71797

Ferlay, J., Colombet, M., Soerjomataram, I., Mathers, C., Parkin, D. M., Piñeros, M., ... Bray, F. (2019). Estimating the global cancer incidence and mortality in 2018: GLOBOCAN sources and methods. International Journal of Cancer, 144(8), 1941-1953. https:// doi.org/10.1002/ijc.31937

Govindaraj, R., Navaratne, K., Cavagnero, E., \& Rao Seshadri, S. (2015). Health care in Sri Lanka: What can the private health sector offer? https://openknowledge.worldbank.org/bitstream/ handle/10986/20018/899540WP0Box380th0Care0in0Sri0Lanka. pdf

Halle-Ekane, G. E., Nembulefack, D. K., Orock, G. E., Fon, P. N., Tazinya, A. A., \& Tebeu, P. M. (2018). Knowledge of cervical cancer and its risk factors, attitudes and practices towards pap smear screening among students in the University of Buea, Cameroon. Journal of Cancer and Tumor International, 7(4), 1-11. https://doi. org/10.9734/jcti/2018/43965

Kangmennaang, J., Onyango, E. O., Luginaah, I., \& Elliott, S. J. (2018). The next Sub Saharan African epidemic? A case study of the determinants of cervical cancer knowledge and screening in Kenya. Social Science \& Medicine, 197(May 2017), 203-212. https:// doi.org/10.1016/j.socscimed.2017.12.013

Kokuro, M. (2017). Factors affecting the utilisation of cervical cancer screening among women attending health services in the Kumasi Metropolis of Ghana. (March).

Liebermann, E. J., Vandevanter, N., Hammer, M. J., \& Fu, M. R. (2018). Social and cultural barriers to women's participation in pap smear screening programs in low- and middle-income Latin American and Caribbean countries : An Integrative Review. J. Transcult Nurs, 29(6), 591-602. https://doi.org/10.1177/1043659618755424

Lim, J. N. W., \& Ojo, A. A. (2017). Barriers to utilisation of cervical cancer screening in Sub Sahara Africa: A systematic review. European Journal of Cancer Care, 26(1), 1-9. https://doi.org/10.1111/ ecc.12444

Mabelele, M. M., Materu, J., Faraja, D. N., Mahande, M. J. (2018). Knowledge towards cervical cancer prevention and screening practices among women who attended reproductive and child health clinic at Magu district hospital, Lake Zone Tanzania: A cross-sectional study. BMC Cancer, 18(1),

Makuza, J. D., Nsanzimana, S., Muhimpundu, M. A., Pace, L. E., Ntaganira, J., \& Riedel, D. J. (2015). Prevalence and risk factors for cervical cancer and pre-cancerous lesions in Rwanda. Pan African Medical Journal, 22, 1-8. https://doi.org/10.11604/ pamj.2015.22.26.7116

Manirakiza, A., Longombe, A. N., Kyamanywa, P., \& Rulisa, S. (2016). Cervical cancer in Rwanda: Why do women consult in late stages? Rwanda Medical Journal, 73(4), 9-11.

McFarland, D. M., Gueldner, S. M., \& Mogobe, K. D. (2016). Integrated review of barriers to cervical cancer screening in Sub-Saharan Africa. Journal of Nursing Scholarship: An Official Publication of Sigma Theta Tau International Honor Society of Nursing, 48(5), 490498. https://doi.org/10.1111/jnu.12232

Mukanyangezi, M. F., Sengpiel, V., Manzi, O., Tobin, G., Rulisa, S., Bienvenu, E., \& Giglio, D. (2017). Screening for human papillomavirus , cervical cytological abnormalities and associated risk factors in HIV-positive and HIV-negative women in Rwanda. HIV Medicine, 19(2)152-166. https://doi.org/10.1111/hiv.12564

Nakisige, C., Schwartz, M., \& Ndira, A. O. (2017). Cervical cancer screening and treatment in Uganda. Gynecologic Oncology Reports, 20, 37-40. https://doi.org/10.1016/j.gore.2017.01.009

Nwobodo, H., \& Ba-Break, M. (2016). Analysis of the determinants of low cervical cancer screening uptake among Nigerian women. Journal of Public Health in Africa, 6(2), 12-19. https://doi. org/10.4081/jphia.2015.484

Racey, C. S., \& Gesink, D. C. (2016). Barriers and facilitators to cervical cancer screening among women in rural Ontario, Canada: The Role of Self-Collected HPV Testing. J Rural Health, 32(2), 136-145. https://doi.org/10.1111/jrh.12136

Ruzigana, G., Bazzet-matabele, L., Rulisa, S., Ghebre, R. G., \& Martin, A. N. (2017). Gynecologic Oncology Reports Cervical cancer screening at a tertiary care center in Rwanda. Gynecologic Oncology Reports, 21(May), 13-16. https://doi.org/10.1016/j.gore.2017.05.005

Santesso, N., Mustafa, R. A., Schünemann, H. J., Arbyn, M., Blumenthal, P. D., Cain, J., ... Broutet, N. (2016). World Health Organization Guidelines for treatment of cervical intraepithelial neoplasia 2-3 and screen-and-treat strategies to prevent cervical cancer. International Journal of Gynecology and Obstetrics, 132(3), 252-258. https://doi.org/10.1016/j.ijgo.2015.07.038

Schiffman, M. (2017). Cervical cancer screening: Epidemiology as the necessary but not sufficient basis of public health practice. Preventive Medicine, 98, 3-4. https://doi.org/10.1016/j. ypmed.2016.12.028

Stewart, T. S., Moodley, J., \& Walter, F. M. (2018). Population risk factors for late-stage presentation of cervical cancer in sub-Saharan Africa. Cancer Epidemiology, 53(September 2017), 81-92. https:// doi.org/10.1016/j.canep.2018.01.014

Tavakol, M., \& Dennick, R. (2011). Making sense of Cronbach's alpha. International Journal of Medical Education, 2, 53-55. https://doi. org/10.5116/ijme.4dfb.8dfd

Thapa, N., Maharjan, M., Petrini, M. A., Shah, R., Shah, S., Maharjan, N., ... Cai, H. (2018). Knowledge, attitude, practice and barriers of cervical cancer screening among women living in mid-western rural, Nepal. Journal of Gynecologic Oncology, 29(4), 1-12. https:// doi.org/10.3802/jgo.2018.29.e57

Titiloye, M. A., Womitenren, Y. T., \& Arulogun, O. S. (2017). Barriers to utilization of cervical cancer screening services among women of reproductive age in Ondo, Southwest Nigeria. African Journal of Biomedical Research, 20(3), 229-235.

Vaccarella, S., Laversanne, M., Ferlay, J., \& Bray, F. (2017). Cervical cancer in Africa, Latin America and the Caribbean and Asia: Regional inequalities and changing trends. International Journal of Cancer, 141(10), 1997-2001. https://doi.org/10.1002/ijc.30901

Zidar, M. N., Larm, P., Tillgren, P., \& Akhavan, S. (2015). Nonattendance of mammographic screening: The roles of age and municipality in a population-based Swedish sample. International Journal for Equity in Health, 14(1). https://doi.org/10.1186/ s12939-015-0291-7 